\title{
Process Design \& Development Using Smed Concept- A Case Study
}

Manjunath. R. Rawal ${ }^{1}$, Sachitanand G. Kanitkar ${ }^{2}$, Amit A. Sasane ${ }^{3}$, Shubham S. Sabale ${ }^{4}$, Prasad V. Kasbekar ${ }^{5}$, Dayanand P. Bhopale ${ }^{6}$

${ }^{1}$ Asst. Professor D.K.T.E's Textile and Engineering Institute, Ichalkaranji-416115

${ }^{2}$ Asso. Professor D.K.T.E's Textile and Engineering Institute, Ichalkaranji-416115

${ }^{3,4,5,6}$ Student, Mech. Dept., D.K.T.E’s Textile and Engineering Institute, Ichalkaranji-416115

Email Id: manjunathrrawal61@gmail.com

\begin{abstract}
The growth of the industry and its production ultimately depends on its ability to respond systematically and continuously to market changes to increase product value. The process of adding value is necessary to obtain this advantage; therefore using a coherent production system and its tools becomes a key skill. Since the set time is the main reason for the production break time, a short set time is always desirable. The Single Minute Exchange of Dies (SMED) as proposed by Shingo is a tool that aims to reduce overtime setting, but does not work when used alone. SMED can be used effectively with the help of additional tools such as FMRS (Finish, Merge, Reduce and Simplify). This paper describes the process of planning and implementing SMED and other useful tools. It is based on a collaborative approach that allows for a gradual reduction in machine set-up time associated with an ongoing continuity program.
\end{abstract}

Keywords: SMED, Lean Manufacturing, Time study, 5S technique.

Introduction: In a time of globalization, manufacturing industries need to increase their flexibility in production through smaller batch sizes. However, this will lead to a significant increase during setup. Therefore, faster setup procedures involving smaller batch sizes and greater flexibility are required for hours. Therefore, the ability to perform quick setup processes is widely recognized as a necessary requirement for flexibility and small batch production. Lean Production aims to systematically identify and eliminate waste through continuous development, facilitating the flexibility and competitiveness of organizations.

Highly dependent production is a production practice that considers the use of resources from any policy other than the value of the customer ultimately as a waste, and thus the goal of elimination. Working from the perspective of a customer using a product or service price is 
defined as an action or process that the customer would like to pay for. SMED (Single Minute Exchange of Die) is one of the most productive forms of production. The need for short-term setups is not new; it's been around for a long time. Indeed, the time between producing the final product of a series, and producing the first product of a new series that meets all quality requirements, has long been considered a waste of production. Recently, in all types of production, there has been an increased focus on reducing waste production, so the need for shorter setups is now much greater than before. Setting can be defined as the time elapsed between the end product A leaving the machine and the first positive product B output.

In short, SMED (Single Minute Exchange of Die) is a dependent tool used to reduce the time it takes to switch from one process to another. In addition to improving cycle time in the process, SMED can help reduce costs and increase flexibility within the process.

\section{SMED Terminologies:}

The SMED concept is the most widely used method to improve the overall setup process. The implementation of SMED allows for an increase in production capacity without adding additional equipment. Some of the names of SMEDs discussed below:

Setup Changeover: Time elapsed between the last pieces in the run just completed until the first good piece from the process after changeover.

- External Setup or Outside Exchange of Die (OED): That part of the setup which can be done while the machine is still running.

- Internal Setup or Inside Exchange of Die (IED): That part of setup which must be done while the machine is shutdown.

- Flexibility: To be able to respond very quickly to changing market demands, you need to be able to produce small lot sizes in a cost-effective way.

- Bottleneck Capacities: Reducing setup times increases the available capacity, which can be interesting as an alternative to buying new equipment or installing an extra shift in situations where the market demand increases.

- Overall Equipment Effectiveness (OEE) = Equipment Availability x Performance Efficiency x Rate of Quality Products SMED methodology is adopted to reduce the setup changeover time and increase the Overall Equipment Effectiveness (OEE)

Steps involved in SMED technique are shown by four stages in figure no. 1. 


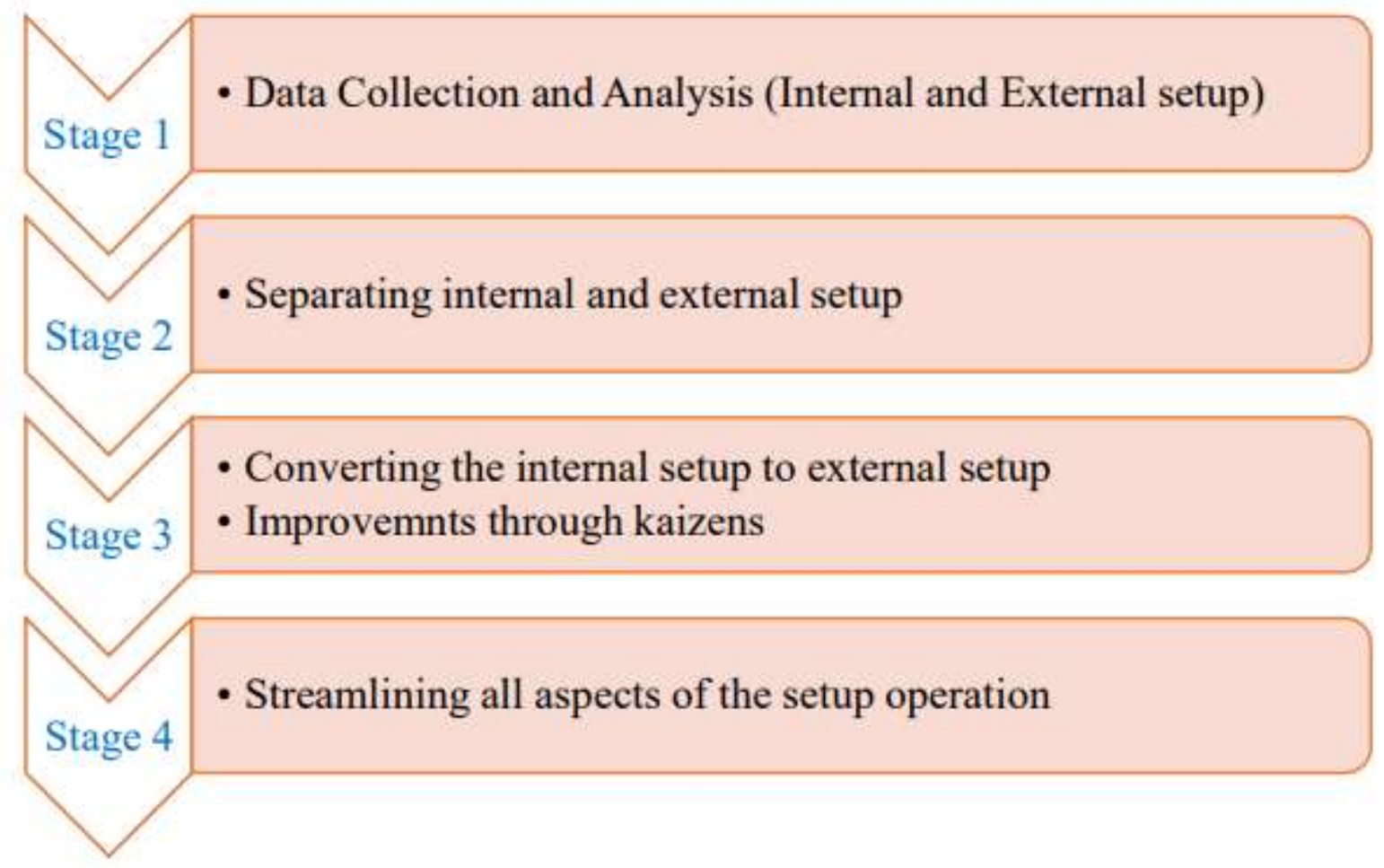

Fig 1: Flow Diagram of SMED Conceptual Stages

\section{Literature Review:}

N. S. Jagtap et.al: This paper outlines the process for planning and implementing SMED and other useful tools. It is based on a collaborative approach that allows for a gradual reduction in machine set time to less than 10 minutes in line with a continuous continuity plan. This paper also presents a case study in the portable manufacturing industry that promotes development that will significantly reduce machine set time 30\% -35\%. Rushikesh Gavali et.al: This paper describes the application of SMED concepts and techniques as self-limiting to the duration of change in sector performance and reflects a live case that has reduced change over time by the 1000 Ton news line. In addition, this function uses the SMED method and other Lean Production tools such as 5S, Visual Management, Kaizen and Standard Work process used to reduce die set time. As a result, the setup time is significantly reduced (from 87 minutes to 60 minutes). The percentage reduction during setup was 18.03\%. Antonio Carrizo Moreira \& Gil Campos Silva Pais: As such, this article has its main purpose in contributing to the literature on the less widely read topic: SMED. A case study was conducted, the main findings are that, through SMED strategies, the company was able to eliminate waste and additional value-added works worth 
approximately $360000 €$, which is about $2 \%$ of the company's sales volume. Eric Costa et.al: This paper describes the improvement of the process of setting up a printing press in place of a mechanical metal company mechanic. The Single-Minute Exchange of Die (SMED) method and other Lean Production tools (5S, Visual Management and Standard Work) were used to reduce the set-up times identified at the beginning. With improved solutions it is possible to reduce setup times, work-in-process (WIP) and staff distances. Jonalee D. Bajpai: This paper discusses the concept and methodology of SMED as a custom to reduce the time of style change in the textile industry and shows a live case that reduces the change of style over time. The result obtained showed a significant reduction in the delay that occurs during machine setup, batch setting time and display delay. Muhamad Nasruldin Bin Hashim: In this project, SMED provided a way to end waste of time with their eight SMED strategies presented by Mr Shigeo Shingo. In the case of SMED mold or death mold should be less than 10 minutes and requires a lot of development involved in the work. They will be able to reduce by up to $51 \%$ of the total set-up time. Jay $\mathbf{V}$ Sureja et.al: Progress before and after the launch of $5 \mathrm{~S}$ is shown in this paper. It also aims to build a strong workforce within management and employees who are expected to continue good practices. Shogo Kanamori et.al: In this paper, 15 art studies highlighted its use in primary health care facilities and various hospital facilities in Brazil, India, Jordan, Senegal, Sri Lanka, Tanzania, the UK and the USA. The review also found that $5 \mathrm{~S}$ was considered the first area in the development of quality health care. Ten studies have reported their effects on quality improvement; the changes caused by the $5 \mathrm{~S}$ system were divided into three levels of safety, efficiency, and patient focus. In addition, the $5 \mathrm{~S}$ was adopted as part of the government's strategy for improving quality in India, Senegal, Sri Lanka and Tanzania. San Chee Houa et.al: This study is a study of the implementation of the $5 \mathrm{~S}$ in the manufacturing industry. Apart from this, the research has focused on the manufacturing industry. In this study, foreign workers play a major role in implementing $5 \mathrm{~S}$ systems as the manufacturing industry in Malaysia accepts a large number of foreign workers to work as laborers. Therefore, it is important to make sure that foreign workers really understand the concept of the $5 \mathrm{~S}$ system and use best practices to make it work better. This study has been suggested by the research model of barriers to the use of $5 \mathrm{~S}$ in the manufacturing industry among external workers. Other research methods have been adopted for research purposes, such as descriptive research design with computational methods, research questionnaires and short-term studies. R.S. Agrahari et.al: This paper was about the 
implementation of the $5 \mathrm{~S}$ method in the small-scale fishing industry. Following the $5 \mathrm{~S}$ method, it shows significant improvements in safety, manufacturing, efficiency and home maintenance. Progress before and after the launch of the $5 \mathrm{~S}$ is illustrated on paper. It also aims to build a strong workforce within management and employees who are expected to continue good practices. Soumya R. Purohit et.al: This paper emphasizes the step-by-step guidelines required for the effective use of the $5 \mathrm{~S}$ as part of daily management practices. It shows how to implement each pillar of the 5S Methodology- Seiri, Seiton, Seiso, Seiketsu and Shitsuke in the industry to make a complete improvement in its performance.

\section{Data Collection and Key Parameters:}

The purpose of a time study is to establish a suitable work schedule to perform a specific task under specified conditions and at a specified level of performance. A detailed analysis of the transition time is set out in Table 1 .

Table 1: Time Study

\begin{tabular}{|c|c|c|c|}
\hline Sr.No. & Description of Process & $\begin{array}{c}\text { Time Elapsed } \\
\text { (min) }\end{array}$ & $\begin{array}{c}\text { Proposed } \\
\text { Time (min) }\end{array}$ \\
\hline 1. & Lifting of core box by fork lift & 2.18 & 1 \\
\hline 2. & To carry core box to machine & 7.23 & 1 \\
\hline 3. & Clear the path way & 5.13 & 0 \\
\hline 4. & To lift core box to $\mathrm{m} / \mathrm{c}$ base plate 1 & 7.46 & 0.30 \\
\hline 5. & Attaching core box to base plate 1 & 5.08 & 2 \\
\hline 6. & To tighten the nut $\&$ bolts for base plate 1 & 5.23 & 0.20 \\
\hline 7. & Attaching core box to base plate 2 & 3.51 & 1 \\
\hline 8. & To separate core box (LHS \& RHS) & 2.20 & 0.5 \\
\hline 9. & To set mandrel & 14.31 & 1 \\
\hline 10. & $\begin{array}{l}\text { Clearing the space to carry the previous core } \\
\text { box to core box rack }\end{array}$ & 5.02 & 0 \\
\hline 11. & Time to set gas plate & 1.12 & 1 \\
\hline 12. & Setting of sand shooting plate & 3.26 & 1 \\
\hline 13. & Cleaning the core box & 1.43 & 0.10 \\
\hline 14. & Greasing the core box by wax/polish & 1.40 & 0.20 \\
\hline 15. & Cycle time for manufacturing core & 1.32 & 1.32 \\
\hline
\end{tabular}




\section{Summary of time study,}

\begin{tabular}{|l|c|}
\hline Time elapsed to carry out the Changeover & $\mathbf{6 9} \mathbf{~ m i n}$ \\
\hline Idle man time & $\mathbf{1 5 . 2 9} \mathbf{~ m i n}$ \\
\hline Total time elapsed & $\mathbf{8 4 . 2 9} \mathbf{~ m i n}$ \\
\hline
\end{tabular}

Following figure no.2 shows the major time loss in setup changeover as per the time study carried out:

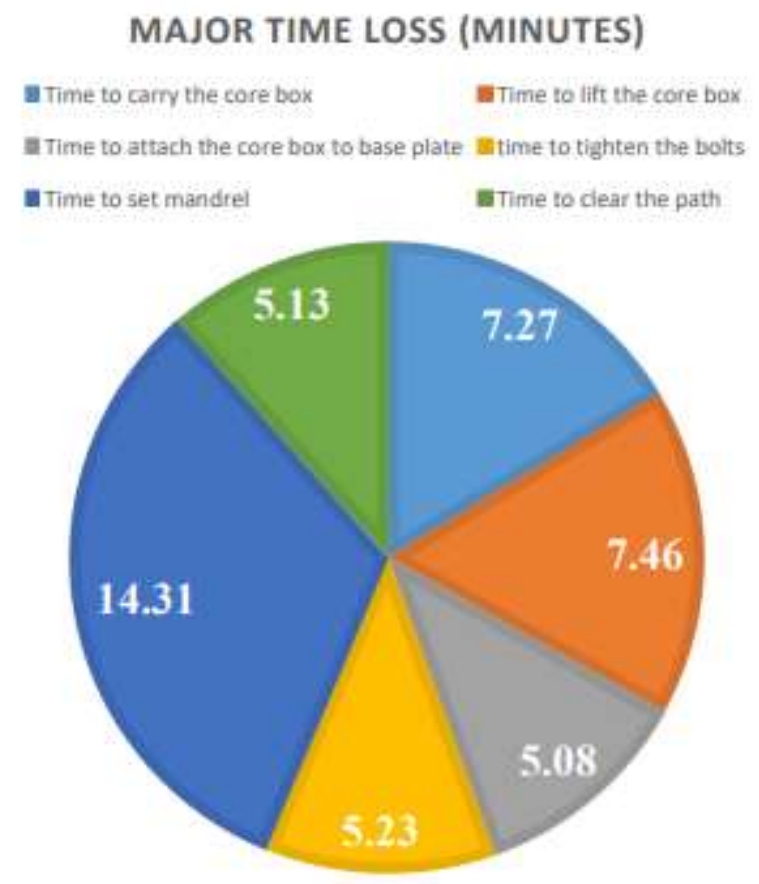

Fig 2: Pi-chart for Major Time Losses

From the time study, some Key parameters are noted which plays major contribution in increasing total time for changeover and work efficiency. Ultimately leads to reduction in production rate and increase in cost of manufacturing. These key parameters are enlisted below and photographs of actual workplace are shown in figure no. 3 .

a) No proper work space allocation for machine.

b) Identification/Part no were not given on the Shooting Plate, Gas Plate \& Mandrel

c) Causing fatigue to the worker to align the core box to the machine's base plate with the help of crane.

d) Time required to clear the path due to unclear path ways.

e) No fix position to place the Shooting Plate, Gas Plate \& Mandrel. 
f) Required tools were not placed properly.

g) Idle man time during the process, due to lack of planning.

h) Use of hexagonal headed bolts in the T-slots (proper tightening is not possible which adds time).

i) Shooting plate, Gas plate \& Mandrel are not cleaned. Hence extra time is needed to clean it.
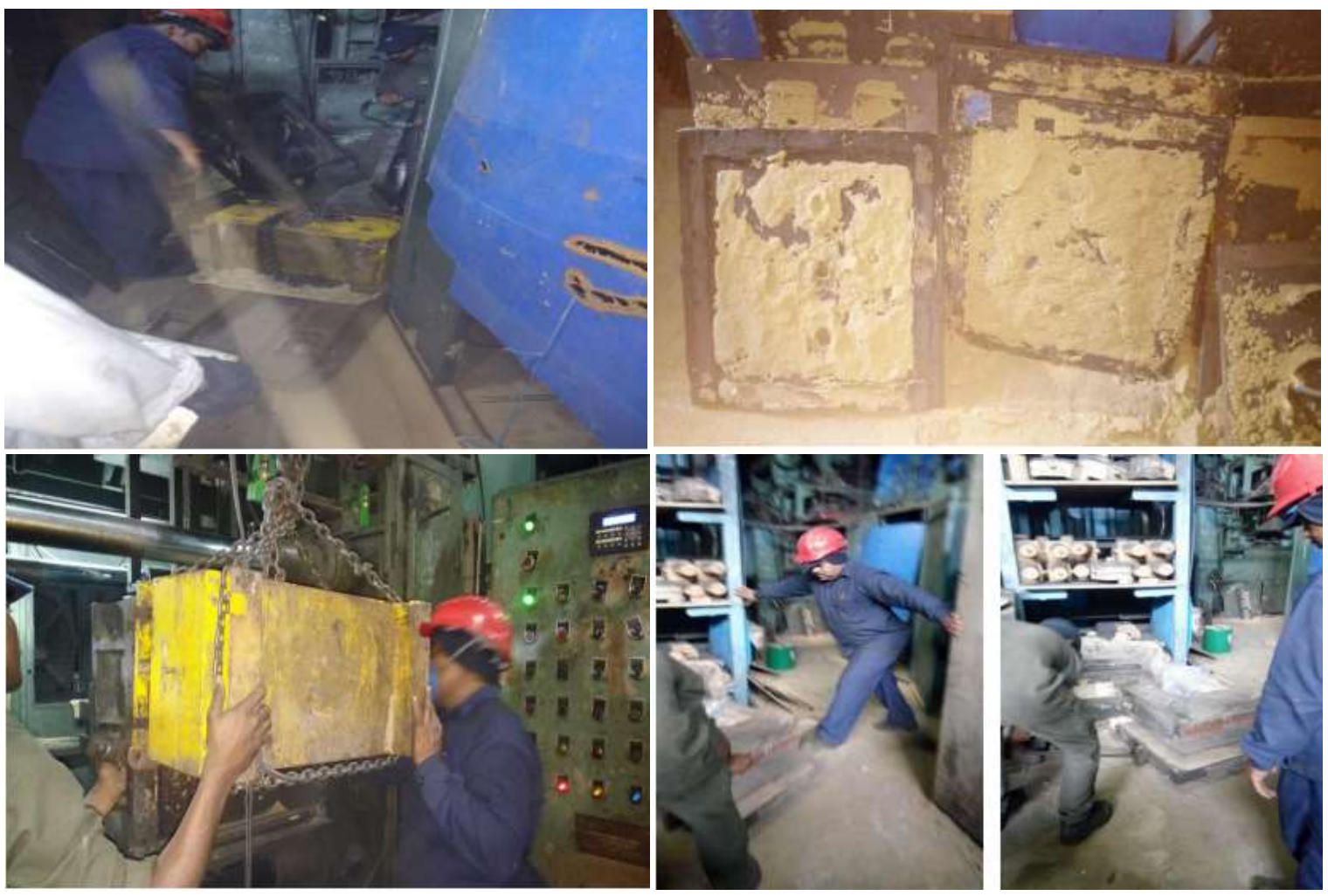

Fig 3: Photographs of some key parameters

Time study and motion study reveals some key findings of process activities carried out during the process, these activities related to plant layout, methods, machines set up and man are analyzed and fish bone diagram is prepared to plan the next activities for improvement in process shown in figure no. 4 . 


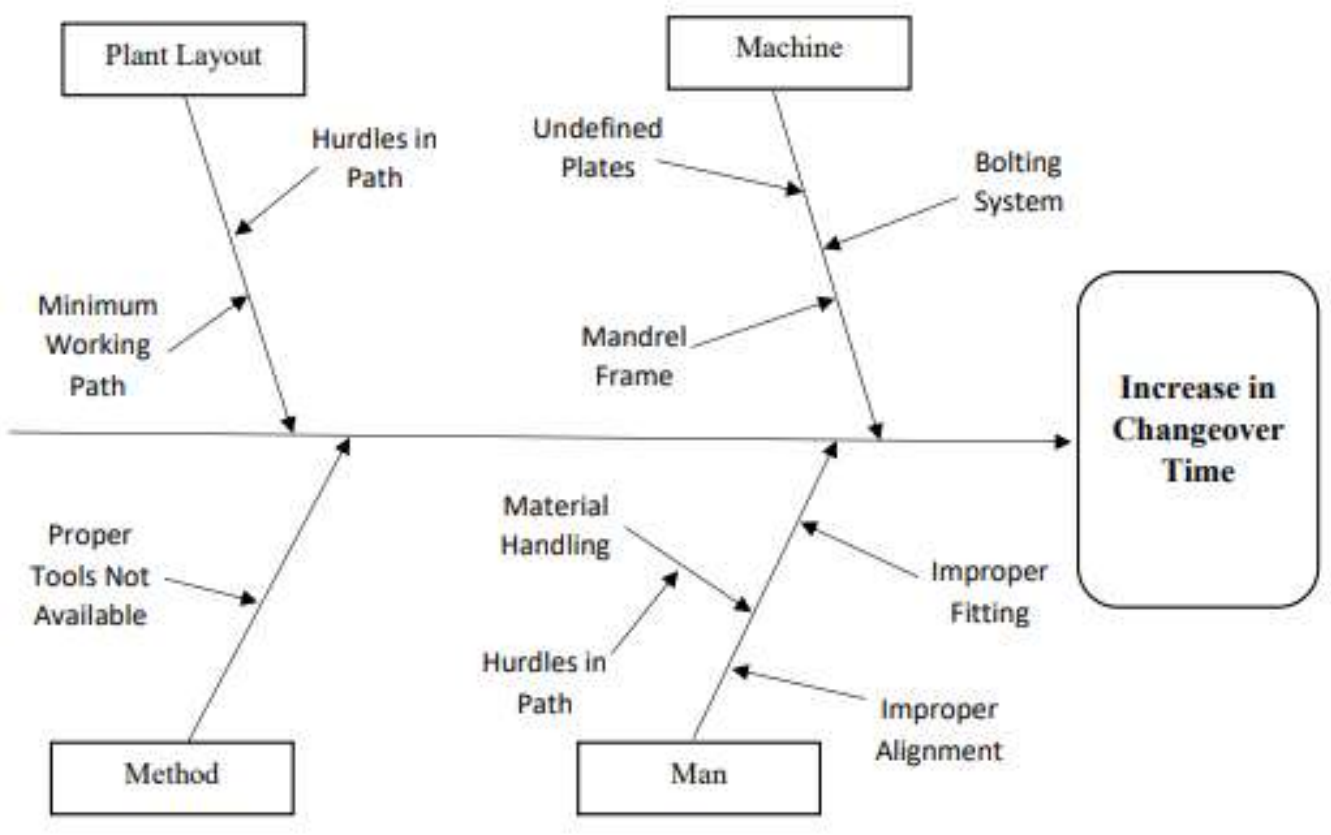

Fig 4: Fish Bone Diagram for Increase in Changeover Time

\section{Improvement Activities:}

As per the problem identification, for the improvement of process- $5 \mathrm{~S}$ system is implemented and changes incorporated are reported below in tabular form for betterment of process activities, shown in table no. 2.

Table No. 2: Problem identification and Improvement

\begin{tabular}{|l|l|l|}
\hline Problem/ Previous Status: & Countermeasure: \\
$\begin{array}{l}\text { Unnecessary shooting or } \\
\text { gassing plates were mixed with } \\
\text { used one \& plates from another } \\
\text { machine also mixed with } \\
\text { current machine (CCM3) }\end{array}$ & $\begin{array}{l}\text { Sorting of essential plates were done \& } \\
\text { Unnecessary plates are discarded. }\end{array}$ \\
\hline
\end{tabular}




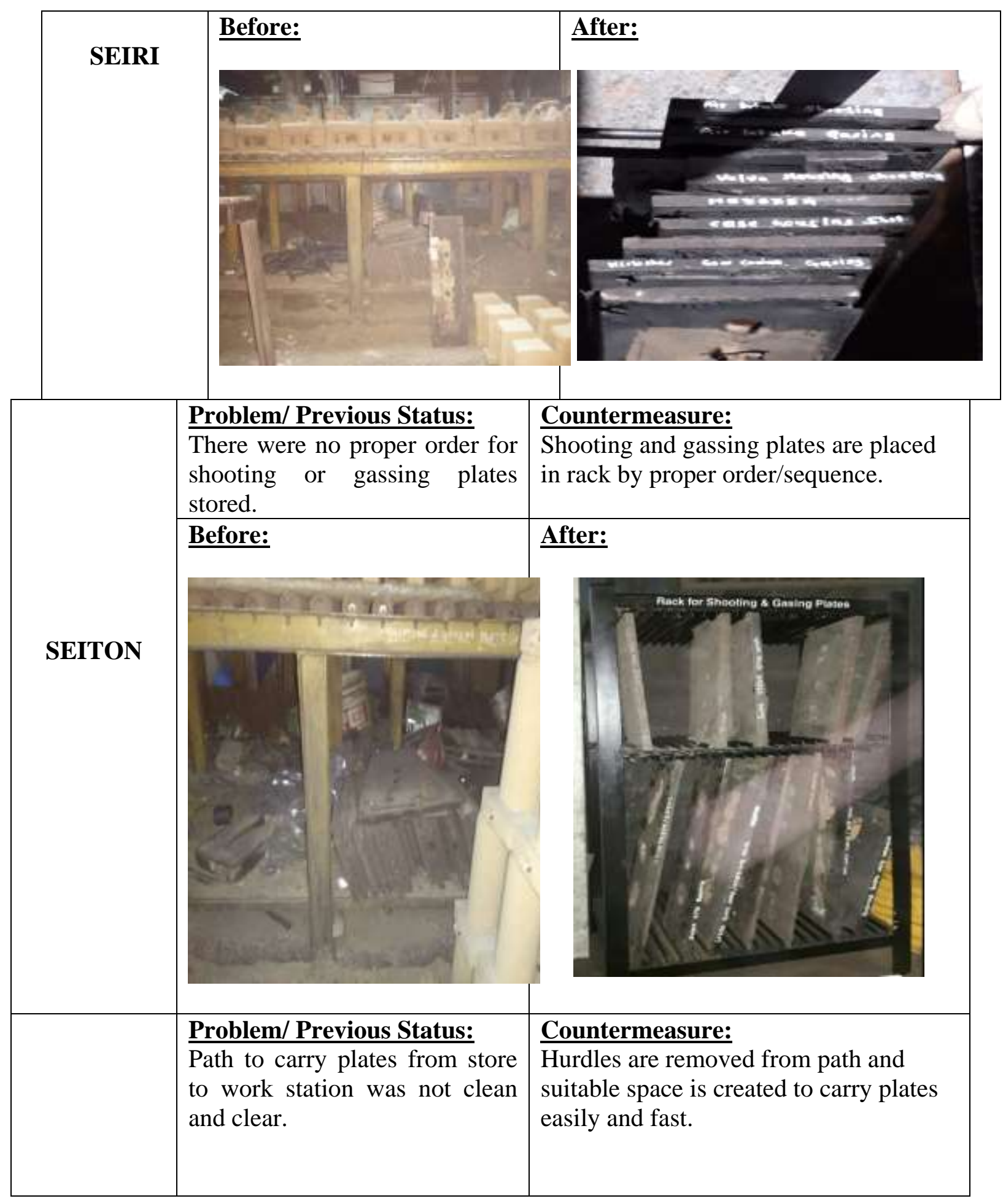




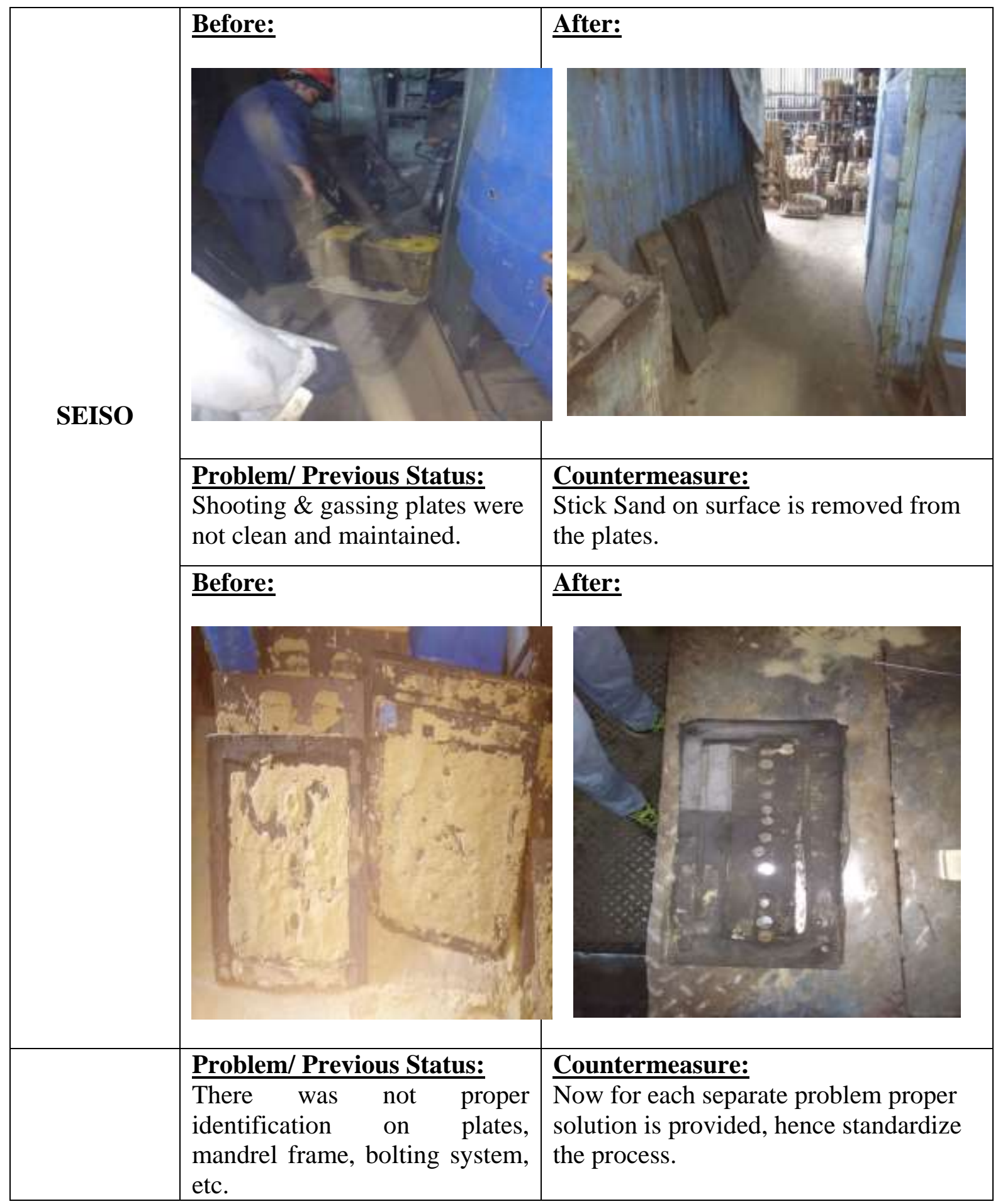




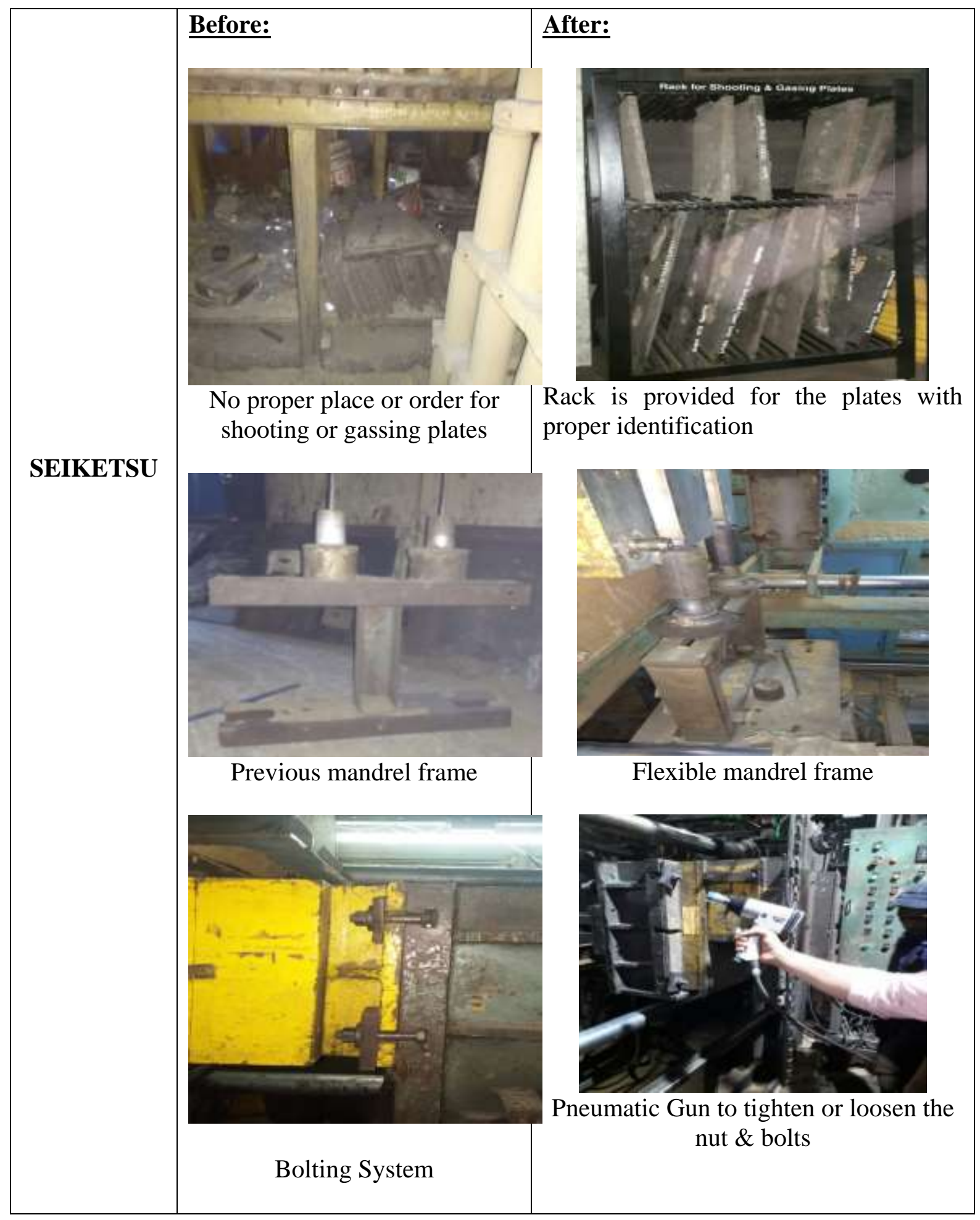




\section{Mandrel Frame Design}

We have created a new mandrel frame that carries all mandrel without any adjustments. Previous mandrel frames had some limitations and design problems. This is due to the alignment of certain functions with certain types of mandrel not proper.
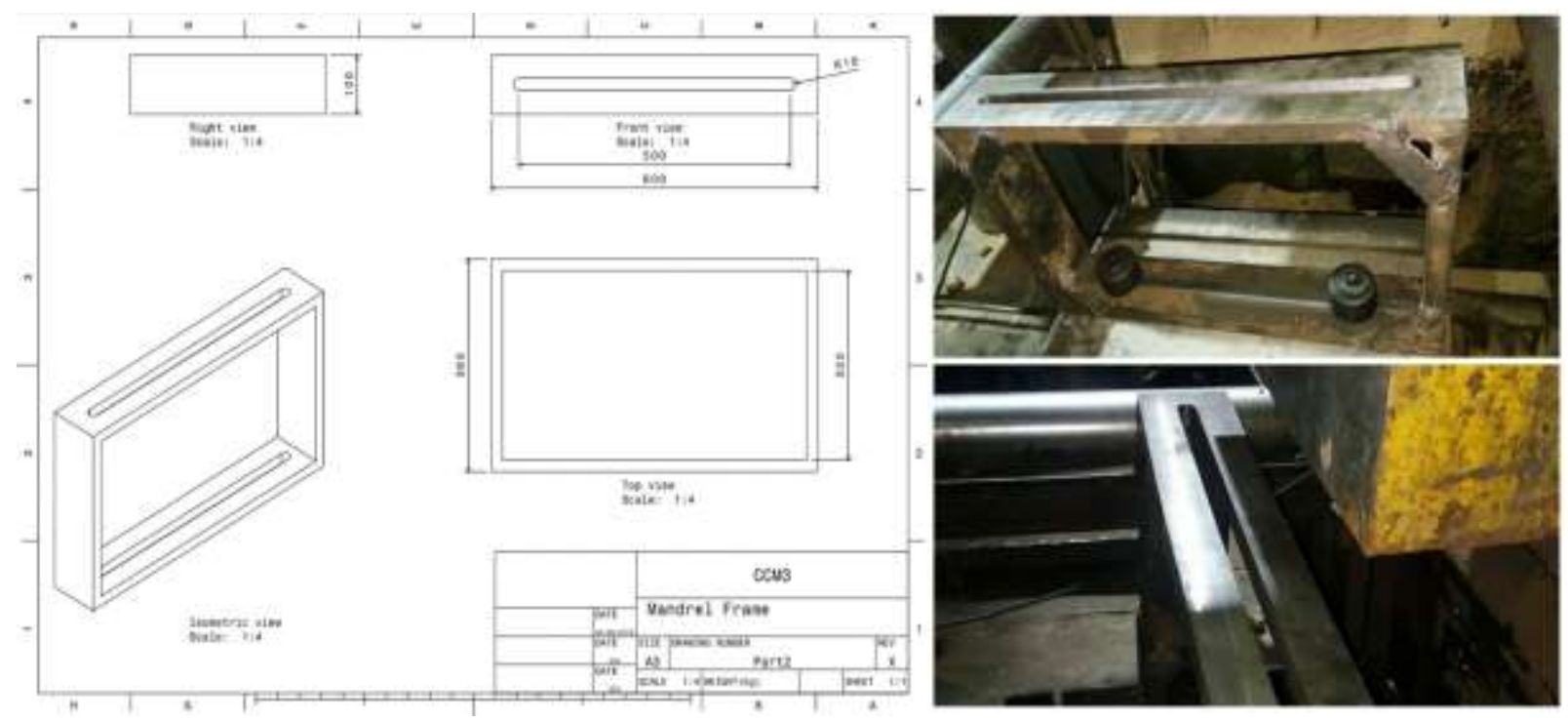

Fig 5: Mandrel Frame (a) Design (b) Fabricated part

Now, this modified design shown in figure no. 5, fulfill all the requirements. It can be a permanent type of setup. There is no need to remove it from all activity. The only requirement is to turn the mandrel over it.

\section{Rack Design:}

The rack is designed for shooting plates \& gas plates to solve problems that occur due to nameless plates as mentioned earlier. This is done to keep these plates with the labeled names in each order. 

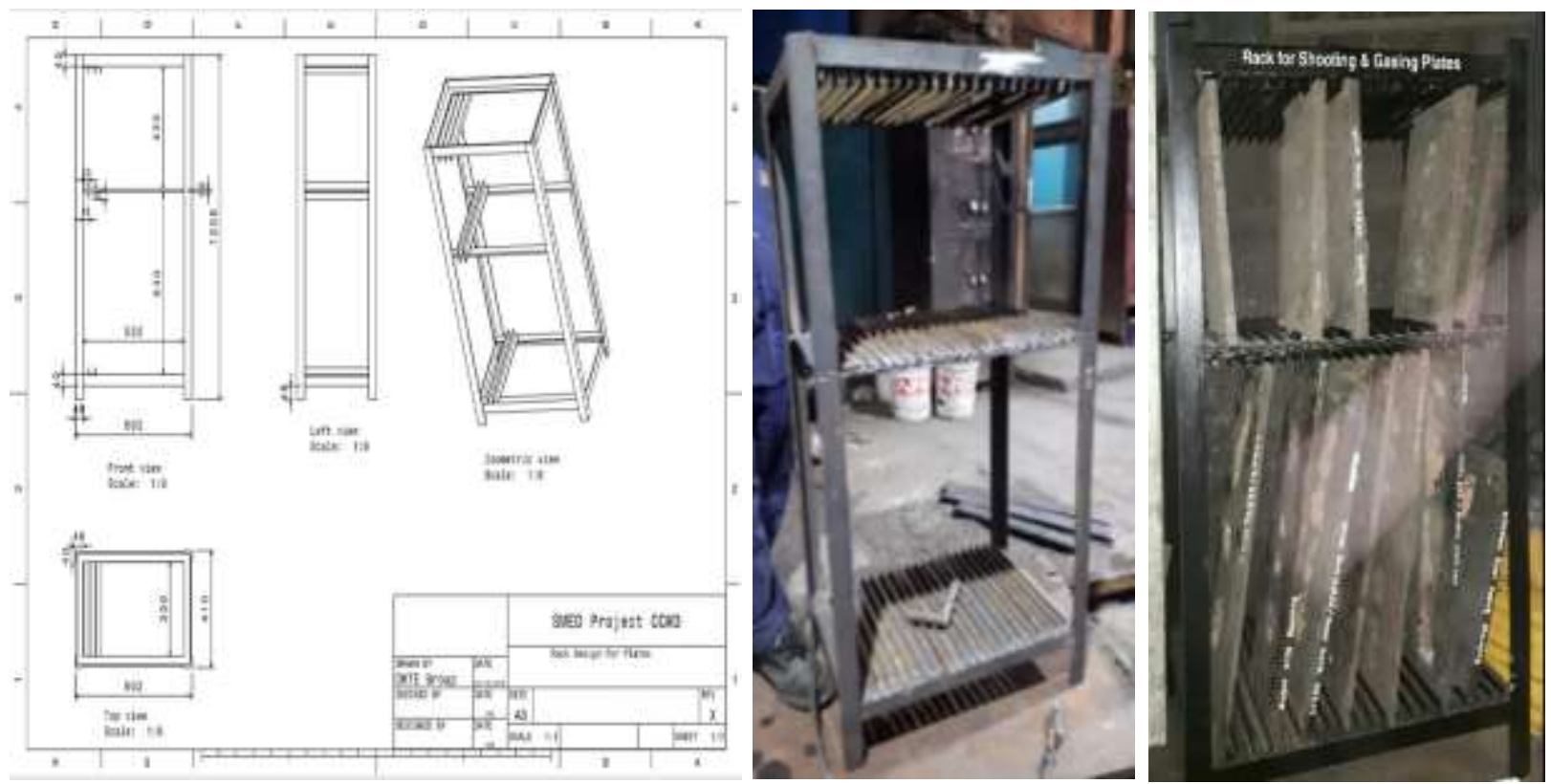

Fig 6: Rack for Shooting \& Gassing Plates

It has two compartments: one for shooting plates (bottom) and one for gas plates (top). It consists of 17 shots and gas plates in each room. As shown in figure no. 6 .

\section{Pneumatic Gun for the Bolting System:}

An air gun is provided to tighten and loosen the nuts / bolts instead of the panel to reduce setting time, Ex. the time required to tighten the core box with a base plate using nut and bolts. The time spent on the strength and flexibility of the bolts is greatly reduced by the air gun as shown in figure no. 7

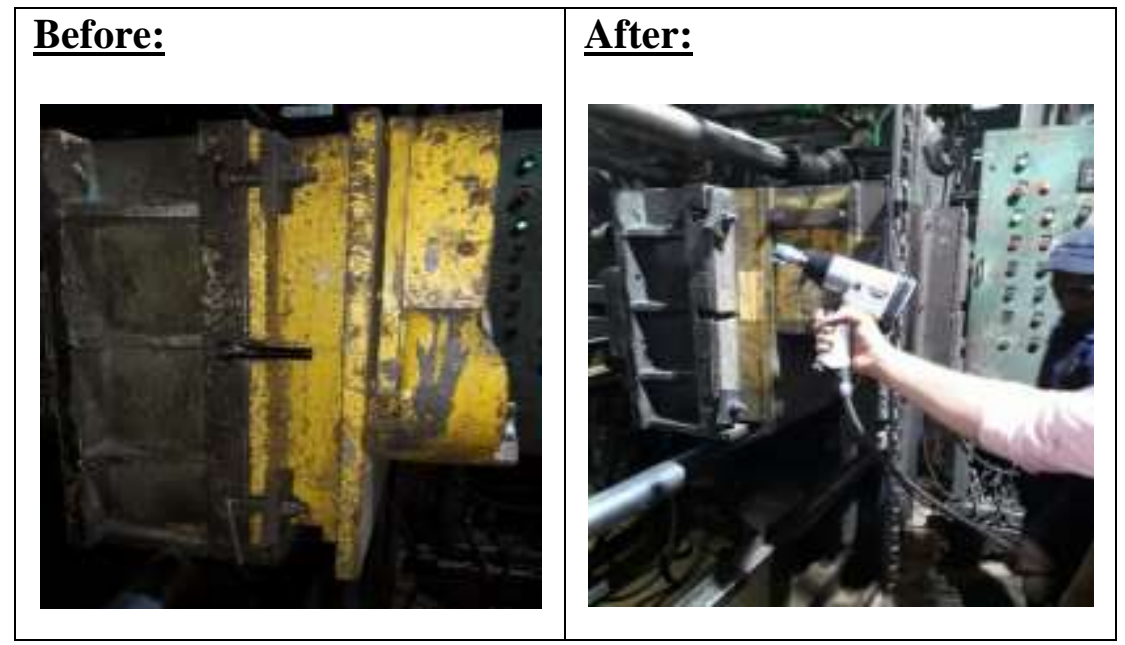

Fig 7: Pneumatic Gun 


\section{Results and Conclusion:}

After implementation of SMED, new time study for the same Machine (CCM3) is carried out. The reduction in changeover time is achieved as shown in following table 3 :

Table 3: Final Time Study

\begin{tabular}{|c|l|c|c|}
\hline \multirow{2}{*}{ Sr.No. } & \multicolumn{1}{|c|}{$\begin{array}{c}\text { Process Parameters Studied for Time } \\
\text { Measurement }\end{array}$} & \multicolumn{2}{c|}{ Time Required (min) } \\
\cline { 3 - 4 } & \multicolumn{1}{|c|}{ Before } & After \\
\hline 1. & Lifting of core box by fork lift & Basic work & Basic work \\
\hline 2. & To carry core box to machine & 7.23 & 1.27 \\
\hline 3. & Clear the path way & 5.13 & 0 \\
\hline 4. & To lift core box to m/c base plate 1 & Basic work & Basic work \\
\hline 5. & Attaching core box to base plate 1 & 5.08 & 2.4 \\
\hline 6. & To tighten the nut \& bolts for base plate 1 & 5.23 & 2 \\
\hline 7. & Attaching core box to base plate 2 & 3.51 & 1.20 \\
\hline 8. & To unscrew the nuts & 6.20 & 1.54 \\
\hline 9. & To separate core box (LHS \& RHS) & 2.20 & 2.20 \\
\hline 10. & To set mandrel & 14.31 & 1.20 \\
\hline 11. & $\begin{array}{l}\text { Clearing the space to carry the previous core } \\
\text { box to core box rack }\end{array}$ & 5.02 & 0 \\
\hline 12. & Gas plate Setting & 1.12 & 0.30 \\
\hline 13. & Setting of sand shooting plate & 3.26 & 1.25 \\
\hline 14. & Cleaning the core box & Basic work & Basic work \\
\hline 15. & Greasing the core box by wax/polish & Basic work & Basic work \\
\hline 16. & Cycle time for manufacturing core & - & - \\
\hline
\end{tabular}



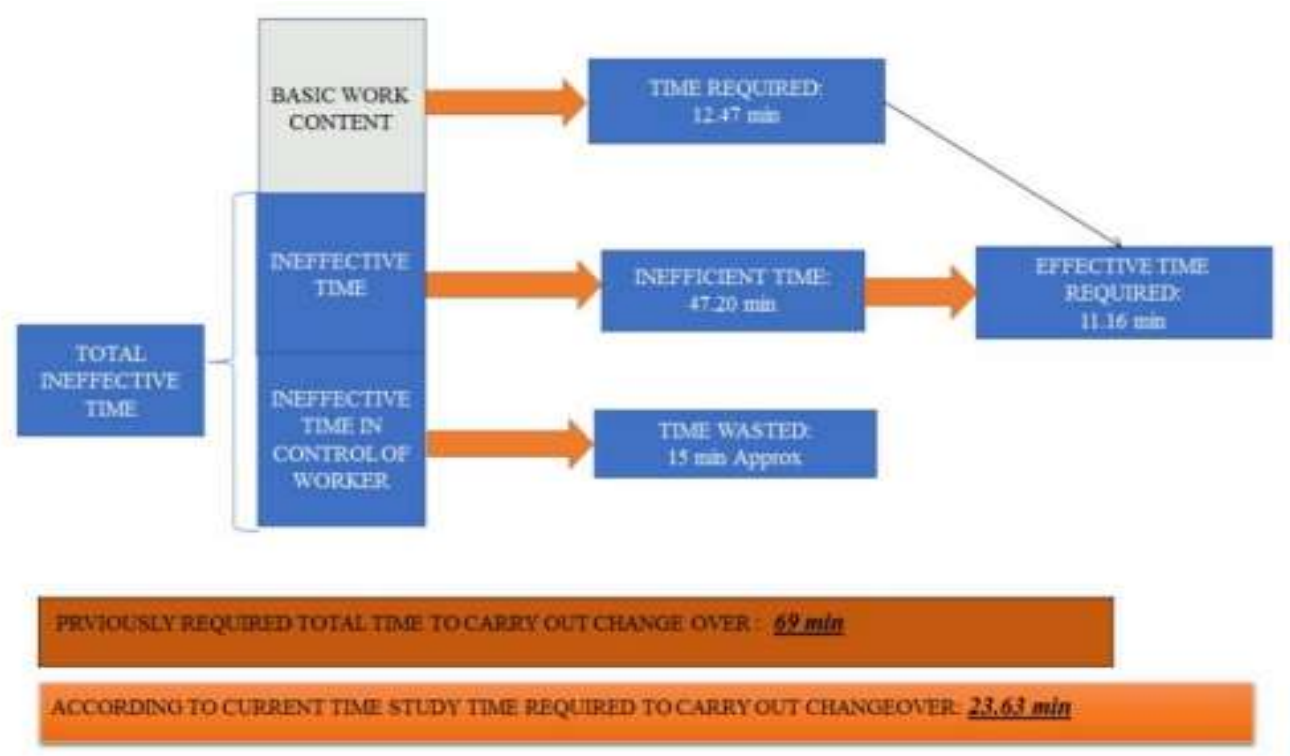

Fig 8: Results of Final Time Study

\section{Increment in Productivity due to SMED:}

Due to implementation of SMED, Increment in production of cores as follows:

- $\quad$ Cost per $\mathrm{kg}$ for core= Rs.15

- Average weight of core $=15 \mathrm{~kg}$

- Production cost per core=Rs. 225

- Cost per batch $=$ No of cores $*$ cost per core $=196$ cores $* 225=$ Rs. $44,100 /$ -

- Reduction time due to SMED = $46 \mathrm{~min}$

- Increment in production due to reduced time $=23$ cores $* 225=$ Rs. $5175 /$ batch

\section{References:}

1. N. S. Jagtap, et.al, "Set-up time reduction of machine using SMED Technique \& Lean Manufacturing," IJAPME, 2015, Volume-1, Issue-2, Page No.7-14.

2. Rushikesh Gavali, et.al, "Set-up Time Reduction of a Manufacturing Line using SMED Technique," IRJET, 2016, Volume-3, Issue-7, Page No.1748- 1750.

3. António Carrizo Moreira, Gil Campos Silva Pais, "Single Minute Exchange of Die. A Case Study Implementation,” J. Technol. Manag Innov., 2011, Volume-6, Issue-1, Page No.129-146.

4. Eric Costa, "An Industrial application of the SMED Methodology \& other Lean Production Tools," IRF, 2013, Page No.1-8.

5. Jonalee D. Bajpai, "SMED (Single-Minute Exchange of Die) methodology in Garment manufacturing Industry: Case study in reducing Style Change over Time," AIMTDR, 2014, Page No.61-1 to 61-7.

6. Muhamad Nusrildin Bin Hashim, "Implementation of SMED Technique to accelerate the Mold Changing Time at SME Company," SME Company Project Report, 2012, Page No.1-24. 
7. Jay V Sureja, et.al, "Application of 5S Methodology in Small Scale Casting Industry," Proceedings of 2nd International Conference on Emerging Trends in Mechanical Engineering, 2017, Page No.253-259.

8. Shogo Kanamori, et.al, "Applicability of the $5 \mathrm{~S}$ management method for quality improvement in healthcare facilities: a review," Tropical Medicine and Health, 2016, Page No.1-8.

9. Sandesh Mali, Prof. A.S. Bhongade, "Implementation of $5 \mathrm{~S}$ in Manufacturing Firm to Reduce Delivery Time of a Product," IIIE, 2017, Volume-10, Issue-9, Page No.37-42.

10. San Chee Houa, et.al, "Implementation of $5 \mathrm{~S}$ in Manufacturing Industry: A Case of Foreign Workers in Melaka," MATEC Web of Conferences 150, 2018, Page No.1-5.

11. R.S. Agrahari, et.al, "Implementation Of 5S Methodology in The Small Scale Industry: A Case Study," IJSTR, 2015, Volume-4, Issue-4, Page No.180-187.

12. Soumya R. Purohit, et.al, "Implementation of $5 \mathrm{~S}$ Methodology in a Manufacturing Industry,” IJSER, 2015, Volume-6, Issue-8, Page No.225-232. 